\title{
A praça: intervenções contemporâneas em espaços de património
}

The square: contemporary interventions in heritage places

Flavio Barbini[i] ${ }^{[0}$ Filipa Ramalhete ${ }^{[b]}$

[a] Arquiteto, doutorando em Arquitetura pelo Instituto Universitário de Lisboa (ISCTE), Centro de Estudos de Arquitectura, Cidade e Território da Universidade Autónoma de Lisboa (CEAC/UAL), Lisboa - Portugal, e-mail: flavio.barbini@gmail.com

[b] Antropóloga, mestre e doutora em Ciências do Ambiente, ramo do Ordenamento do Território do Centro de Estudos de Arquitectura, Cidade e Território da Universidade Autónoma de Lisboa (CEACT/UAL), investigadora do e-GEO - Centro e Estudos de Geografia e Planeamento Regional da Faculdade de Ciências Sociais e Humanas da Universidade Nova de Lisboa, Lisboa - Portugal, e-mail: framalhete@netcabo.pt

\section{Resumo}

Na cidade portuguesa contemporânea, a praça constitui uma herança urbanística de matriz europeia cujo valor patrimonial é fundamental como parte da história urbana, mas também de sua vivência e memória. Essa matriz foi, posteriormente, exportada para países não europeus, tornando-se indispensável na cidade colonial. Nos últimos 20 anos, as políticas urbanas de salvaguarda e conservação dos centros históricos deram origem a três tipos de ações de remodelação de praças: intervenções da responsabilidade dos serviços técnicos das câmaras municipais; intervenções resultantes de concursos públicos, lideradas por arquitetos; intervenções sob encomenda direta, geralmente coordenadas por arquitetos de reconhecido mérito nacional e internacional. Nesse contexto, existem duas metodologias de projeto fundamentais: de cariz estritamente conservacionista ou mais abertas a uma reinterpretação contemporânea de modelos, desenhos e sistemas construtivos resultantes da cultura urbana local. A opção por uma dessas abordagens é, frequentemente, marcada pela época em que é realizada e está fortemente relacionada com a produção teórica e as cartas e recomendações de organismos internacionais existentes e também com uma prática associada a uma disciplina de intervenção em arquitetura, regida por influências globalizantes. Neste artigo, propõe-se a análise do contexto português, tendo como ponto de chegada um duplo objetivo: fornecer uma análise urbana da intervenção na cidade consolidada, identificando as inflexões fundamentais que lhe deram origem; e estabelecer as bases para um projeto de investigação congénere no espaço da lusofonia, que identifique eventuais semelhanças e dissemelhanças, conducentes ao estudo de uma hipótese de existência de lusofilias urbanas contemporâneas dentro dessa temática.

Palavras-chave: Praça. Arquitetura contemporânea. Património. Espaço público. 


\section{Abstract}

In the contemporary Portuguese city, the square is an urban legacy with a European matrix, whose asset value is crucial as part of the urban history, but also its experience and collective memory. This matrix was subsequently exported to non-European countries, becoming indispensable in the colonial city. Over the past twenty years, urban policies of safeguarding and preserving historical centers resulted in three types of actions for remodeling squares: interventions under the responsibility of technical services of municipalities; interventions resulting from public tenders, led by architects; interventions under order direct, usually coordinated by architects renowned nationally and internationally. In this context, there are two fundamental design methodologies: one more conservationist and one more open to a contemporary reinterpretation of models, drawings and building systems resulting from a local urban culture. The choice of one of these approaches is often set by the time in which it is performed and is strongly related to the theoretical production and letters and recommendations of existing international bodies, as well as a practice associated with an intervention in architecture, governed by globalizing influences. This paper proposes the analysis of the Portuguese context, having as a point of arrival, a dual purpose: to provide an analysis of urban intervention in the consolidated city, identifying key inflections which prompted it; lay the groundwork for a research project within the Portuguese-speaking communities, identifying possible similarities and dissimilarities, leading to the study of a hypothesis of contemporary urban lusophilia within this theme.

Keywords: Square. Contemporary architecture. Heritage. Public space.

\section{A praça: de uma matriz urbana europeia a um património de valor local}

\section{Breve nota histórica sobre a praça europeia'}

Na cidade portuguesa contemporânea, a praça constitui uma herança urbanística, cujas origens remontam à cidade grega e romana.

De facto, para procurarmos uma matriz tipológica da praça, que focalize os aspetos compositivos e morfológicos, palco dos principais acontecimentos urbanos, temos de recuar até à antiguidade clássica.

Ao longo de cerca de dez séculos (do século $\mathrm{V}$ a.C. a 465 d.C.), a ágora grega e o fórum romano desempenharam a função de espaços sagrados, de comércio, da administração e representação do poder, ou seja constituem os lugares privilegiados das principais atividades da pólis grega e da cívitas romana. Eram os espaços públicos de exceção na malha urbana, localizados, de preferência, no centro da urbe (principalmente o fórum) (GROS; TORELLI, 2010).
Tendo como adquirido o facto de essas duas tipologias de espaço público constituírem o ponto de partida para o conceito de praça, apta a desempenhar inúmeras funções congregadoras e identificadoras da identidade urbana, resta a pergunta: o que aconteceu nas épocas seguintes? A praça, que se desenvolveu ao longo de séculos, manteve o caráter das antigas ágoras e fóruns?

Se analisarmos a definição de Praça de Enrico Guidoni, que, no séc. XX, realizou um estudo aprofundado sobre as praças na Idade Média e do Renascimento, encontraremos pontos em comum com essas matrizes tipológicas, que permitem confirmar o facto de estarmos a tratar do mesmo tema:

Storicamente la piazza è definibile come uno spazio di uso pubblico e di significativa qualità architettonica e urbanistica, convergenza (o baricentro) di un determinato territorio urbano. L'unicità della piazza rispetto all'insediamento e al territorio trae la sua origine dalla comunità di

\footnotetext{
1 Os dados apresentados neste texto resultam de uma investigação de doutoramento em Arquitetura em curso, realizada por Flavio Barbini, com orientação de Ana Vaz Milheiro e coorientação de Filipa Ramalhete, no ICSTE - Instituto Universitário de Lisboa, com o apoio da Universidade Autónoma de Lisboa.
} 
villaggio: lo spazio centrale è il luogo sacro alle cerimonie e a tutte le principali attività collettive, di convergenza dei percorsi territoriali, della simbolica centralità della comunità rispetto al mondo (GUIDONI, 1992, p. 51-52).

A praça surge, assim, como espaço de utilização coletiva e de significativa qualidade arquitetónica, lugar sagrado para cerimónias e atividades coletivas, ponto de convergência dos percursos do território e lugar simbólico da centralidade da comunidade, aspetos que nos remetem diretamente para a essência da ágora e do fórum da antiguidade clássica.

Apesar desses pontos em comum, o percurso evolutivo que deu origem à praça medieval e à praça da cultura humanista não foi linear. Ou seja, tal como refere Rogério Vieira de Almeida (2012), não se consegue estabelecer um fio condutor direto entre o lugar de implantação dos fóruns e a localização das praças como se de um palimpsesto se tratassem. A explicação é muito simples: primeiro, nem todas as cidades europeias tiveram uma matriz romana, $\mathrm{e}$ segundo, porque mesmo tendo sido planeadas respeitando as rígidas regras de fundação e implantação da quadrícula regrada pelo cardo e decumanus, a maior parte delas foi assaltada, saqueada, posta em chamas e destruída. Ambrosio, Bispo de Milão, em 387, fala de "semirutarum urbium cadavera, terrarumque sub eodem conspecto exposita funera" ("cadáveres de cidades semidestruídas e ao mesmo tempo ruínas de terras") (GROHMANN, 2003, p. 7).

Nesse contexto, assiste-se a uma mudança de direção em relação à continuidade das estruturas materiais, morfológicas e espaciais das cidades clássicas, ao longo de toda a Idade Média. Não existem fóruns e ágoras que originaram praças, em épocas sucessivas. Os únicos exemplos de praças medievais em continuidade com preexistências clássicas coincidem com o reaproveitamento de edifícios singulares, como anfiteatros (Praça de Lucca e Praça do Comércio em Coimbra) e circos (Praça Navona em Roma) e não com fóruns (ALMEIDA, 2012).

Como vimos, se do ponto de vista morfológico não encontramos continuidade direta entre o fórum e a praça medieval, no que concerne ao caráter e ao espírito de vivência desses espaços, podemos constatar que, nas principais praças da Europa meridional, perpetuou-se a relação entre cidadão e praça, entre vida pública e o único lugar central e desafogado da densidade urbana (SITTE, 2007, p. 30).

A grande novidade é que a cidade da Idade Média é o lugar do exercício não só do poder religioso e laico, mas também da economia agrícola, artesanal e monetária, sede de inúmeras atividades que precisam de edifícios públicos e espaços livres abertos (GROHMANN, 2003, p. 7). As atividades coletivas que caracterizam essa organização social desenvolvem-se nas ruas e nas praças, tendo como cenário a própria cidade, onde todo o construído habitado passa a ser o espaço público de excelência. Em muitos casos, as praças são o resultado do alargamento daquelas e a elas estão intimamente ligadas. As praças especializam-se, nasce a praça do mercado, a praça religiosa e a praça pública, caracterizadas pelos edifícios representativos dos diferentes poderes e atividades: a loggia do mercado, a catedral e o palácio público (DENTI, 1985, p. 75-77).

Paralelamente à difusão desse modelo, assistimos à fundação dos novos centros de matriz agrícola (séc. XIII), por iniciativa cisterciense, onde a única praça do mercado é o resultado de uma planificação regular em xadrez, com um sistema de dupla cruz de ruas principais que delimitam uma área quadrada, equivalente a um inteiro quarteirão. É o caso das hospitalitas, nos territórios da Silésia, Boêmia, Polônia (Trzebnica, Novy Jicin, Ceské Budejovice) e ainda das bastides do sudoeste francês (Mirande, Marciac, Solomiac, Beaumont-de-Lomagne e Grenade).

Nasceram cidades planeadas com praça quadrada também na península itálica (Lodi) e em Espanha (Villareal) (GUIDONI, 1989).

O século XIII foi o período em que se verificou o maior número de fundações de cidades, incluindo em Portugal. A fundação delas era acompanhada da outorga de uma carta de foral ou equivalente, em que se definiam os privilégios, os direitos e os deveres dos seus habitantes (TEIXEIRA, 2001, p. 25).

Em quase todos os casos, falamos de cidades planeadas segundo um desenho regular, rodeadas por uma muralha. 0 processo fundacional estava ligado à reconquista de território conquistado aos mouros, principalmente nas terras de fronteira ou em áreas despovoadas (Viana do Castelo, Monção, Caminha, Miranda do Douro, Vila Real, Monsaraz, Vila Viçosa, entre outras). A praça muitas vezes não surgia desde o início, ao contrário do que aconteceu no resto da Europa, e ocupava geralmente terreiros 
ou largos junto à muralha. A praça formal surge séculos mais tarde (XV e XVI), impulsionada pelas renovações urbanas juntamente com a construção de novos edifícios institucionais como Misericórdias, Igrejas e Paços do Conselho. É o caso da Praça Nova (séc. XVI), em Ponta Delgada, aberta diretamente ao mar, ou da Praça Velha de Viana do Castelo (séc. XV), estruturada junto à Igreja Matriz, ou ainda da Praça de Nisa (séc. XVI), junto à Igreja da Misericórdia.

Esta matriz foi, posteriormente, exportada para países não europeus, nomeadamente para os países colonizados, tornando-se indispensável na cidade colonial de origem portuguesa, onde o paradigma urbanístico que inclui a praça europeia foi, depois, aplicado nas novas cidades coloniais. Nelas, a praça constituía um importante espaço de representação, tal como o define Lefébvre (1986), constituindo expressão espacial do poder do estado colonial, como podemos observar nos exemplos das cidades coloniais portuguesas no Brasil (Salvador da Bahia, 1551), onde as múltiplas praças foram integradas desde o início na cidade planeada (TEIXEIRA, 2001). Com o séc. XVII e XVIII, nos traçados urbanos Pombalinos e Joaninos, a praça iluminista, em Portugal e no Brasil, ganha um protagonismo nunca tido até a época. Esse espaço público, de forma quadrada ou retangular, é geralmente o ponto de partida para a estruturação das ruas e de toda a malha urbana ortogonal (Lisboa Pombalina e Vila Real de Santo António). As praças especializam-se, normalmente associadas a um edifício público ou religioso. Já nos casos das cidades coloniais portuguesas do séc. XX, estudados por Ana Vaz Milheiro na Guiné-Bissau e Angola (MILHEIRO, 2012), é na praça que se situam os edifícios que albergam os representantes do poder do Estado, muitos deles chegados da metrópole distante. É habitualmente no seu centro onde são colocados elementos escultóricos alusivos à grandeza do império. Após a independência dos diversos países verifica-se que a praça resiste enquanto elemento urbanístico de referência e que se mantém seu estatuto como espaço simbólico. Os objetos de poder nela colocados são substituídos, mas a representatividade e o valor simbólico do espaço persistem, reafirmando a adaptabilidade do modelo urbanístico da praça a novas realidades sociais e a sua capacidade para manter o seu papel na história das cidades.

Muitos dos estudos sobre forma urbana (CONZEN, 2004, por exemplo) revelam a intrínseca relação entre ela e a história e a civilização que lhe estão subjacentes. Tal como Catanese e Snyder referiam, já em 1979, "Only on rare occasions does urban planning start from scratch; usually it deals with physical, economic, social, and political conditions that have been in place for a long time" (CATANESE; SNYDER, 1979, p. 1).

Não é, dessa forma, surpreendente que a forma urbana - e, nesse caso concreto, a praça - seja vista como parte integrante de um património cultural comum (utiliza-se como definição de património cultural a preconizada no art. $2^{\circ}$ da Lei de Bases do Património Cultural portuguesa: bens testemunho de valor de civilização ou de cultura portadores de interesse cultural relevante). Alguns documentos internacionais cimentam esse pressuposto. A Carta de Veneza, um dos documentos fundadores do pensamento contemporâneo, produzido no âmbito do I Congresso Internacional dos Arquitetos e Técnicos de Monumentos Históricos, deixava já antever, na definição de momento histórico, a importância do valor patrimonial da praça histórica, inserida num determinado contexto histórico e urbano: "não só as criações arquitetónicas isoladamente, mas também os sítios, urbanos ou rurais, nos quais sejam patentes os testemunhos de uma civilização particular, de uma fase significativa da evolução ou do progresso, ou algum acontecimento histórico", em art. 1ํ da Sociedade para a Preservação do Património (SPCC, 1996). Mais tarde, em 1987, a Carta de Washington (Carta para a Salvaguarda das Cidades Históricas, adotada pela Assembleia Geral do Icomos - International Council for Monuments and Sites) afirma especificamente, em seus princípios e objetivos, que os valores a preservar para a salvaguarda de cidades e conjuntos históricos resultam de um conjunto de aspetos materiais e imateriais ("espirituais") que exprimem uma imagem, incluindo "a forma urbana definida pela malha fundiária e pela rede viária" (SPPC, 1996).

\section{Da herança urbana à valorização patrimonial}

Dessa forma, a praça representa um elemento urbanístico cujo valor patrimonial reside em seu enquadramento no contexto da história urbana, mas também em seu papel como elemento polarizador de práticas sociais criadoras de memória e 
identidade coletivas. Segundo Choay (2000), terá sido Aloïs Riegel, em 1907, quem primeiro associou o conceito de valor ao de património, ao considerar que os monumentos possuem valor utilitário e artístico, para além da incerteza das dimensões afetiva e cognitiva do património. Hoje, a noção de valor está intrinsecamente ligada às múltiplas definições de património, progressivamente mais complexas e alargadas (AUDRERIE, 2003). Nesse contexto, a praça é também testemunho de uma vivência e memória coletiva, um espaço que suporta um conjunto de práticas sociais. Embora não dissociável da envolvente, até porque a praça está sempre associada a seu contexto histórico, urbano e social, ela constitui espaço singular, onde ocorrem muitas vezes dinâmicas sociais que não existem noutros locais.

Um exemplo interessante é o da Praça do Comércio, em Lisboa. Tratando-se da maior praça portuguesa, parte marcante e simbólica do plano de reconstrução da Baixa Pombalina após o terramoto e o maremoto de 1755, que destruíram toda a baixa da cidade, assume papel preponderante na afirmação identitária do discurso municipal oficial e um valor patrimonial reconhecido pela população, gerando dinâmicas próprias e alojando acontecimentos únicos na história da cidade e mesmo do país (RAMALHETE, 2009). A recente remodelação da praça, finalizada em 2012, foi acompanhada de intensa polémica e debate público, o que reafirma sua importância como elemento patrimonial nacional, demostrando que seu valor transcende em muito sua vertente urbanística e histórica, adquirindo dimensão simbólica e de representação.

Tendo em conta o exposto, há que considerar que intervir em locais aos quais é atribuído, pelas instituições e pela população, valor patrimonial, implica intervir em espaços multidimensionais, com características únicas e, muitas vezes, complexas. A intervenção contemporânea em espaços históricos tem sido alvo de acesa discussão no âmbito das várias disciplinas que estudam e intervêm nesses territórios. No que diz respeito à praça, este texto pretende contribuir para o debate por meio da análise do caso português. Em seguida, apresenta-se análise de casos de estudo que ilustram as políticas e modelos de intervenção contemporânea.
Políticas e modelos de intervenção contemporâneos na praça histórica

As intervenções arquitetónicas contemporâneas nas praças da cidade consolidada - fortemente patrimonializada e assente em práticas sociais que reforçam seu papel na produção e reprodução de espaços que se assumem como utilitários para a cidades, mas geridos e intervencionados tendo como base o reconhecimento coletivo de seu valor simbólico e histórico - são orientadas por premissas que operam processos de reconhecimento formal da importância desses espaços enquanto mediadores entre a cidade e seus habitantes. Essas refletem abordagens distintas de intervenção, às quais estão subjacentes diferentes conceptualizações de património.

Nos últimos 20 anos, as políticas urbanas de salvaguarda e conservação dos centros históricos deram origem a três tipos fundamentais de ações (todas elas de iniciativa pública, uma vez que é o Estado, central ou local, quem tutela o espaço público) para a remodelação das praças nos centros históricos: intervenções da responsabilidade dos serviços técnicos das câmaras municipais; intervenções resultantes de concursos públicos, lideradas por arquitetos; intervenções sob encomenda direta, geralmente coordenadas por arquitetos de reconhecido mérito nacional e internacional. Nesse contexto, delinearam-se metodologias de intervenção de caráter conservacionista e projetos mais abertos a uma reinterpretação em chave contemporânea de modelos, desenhos e sistemas construtivos resultantes da cultura urbana local. Essas correntes estão fortemente relacionadas com a produção teórica e as cartas e recomendações de organismos internacionais, como a Unesco ou o Icomos. No entanto, são também indissociáveis do contexto arquitetónico internacional e de uma prática associada a uma disciplina de intervenção em arquitetura, regida por influências globalizantes. Das duas metodologias, a primeira inscreve-se no âmbito de intervenções de conservação, no qual, após levantamento que inclui um exame histórico, técnico e artístico, recuperam-se os materiais originais como os predominantes na intervenção a realizar. Esse tipo de atuação refere-se a lugares de reconhecido valor 
artístico, arquitetónico e patrimonial e praças cujas superfícies não sofreram grandes alterações ao longo do tempo. A esse propósito remetemos às teorias de Giovannoni (1873-1947) que considerava o restauro uma operação "científica", com a finalidade de conservar o "monumento" bem como o "ambiente monumental" a sua volta (AVETA, 2005, p. 11).

Nos outros casos, dos quais é exemplo uma série de intervenções em praças nas principais cidades da Europa, concluídas nos últimos 20 anos, a posição metodológica de intervenção não só compreende análise detalhada da história e cultura arquitetónica do local, e a natureza do próprio espaço, mas também enquadra novas dinâmicas de uso do espaço vazio e do edificado contíguo. Tomando como exemplo um trabalho exaustivo de recolha de 60 casos de estudo, elaborado no âmbito do projeto Square of Europe, Squares for Europe, que resultou numa exposição itinerante com o mesmo nome, coordenada pelo arquiteto italiano Franco Mancuso, percebe-se como as diferentes atuações, independentemente de suas especificidades onde "cada caso é um caso", tinham como objetivo a recolocação da praça como símbolo e centro nevrálgico da cidade, sede de eventos públicos, onde o cidadão consegue reencontrar o seu espaço identitário e sua história.

Em quase todos os casos, distribuídos por 22 países, procurou-se um novo equilíbrio entre o peão e o espaço para o trânsito automóvel com novas soluções de parques enterrados ou através do condicionamento do trânsito. Valorizou-se o desenho do pavimento como elemento identificador e gerador de novas relações entre o edificado envolvente, recuperando materiais locais de grande resistência e durabilidade para a programada multifuncionalidade. Em alguns casos, a água é reintroduzida como elemento simbólico, muitas vezes como parte de um sistema de canais ao ar livre ou por meio de espelhos de água.

Independentemente das questões formais e de projeto, o que se pretende salientar nesses casos é uma viragem de tendência que recoloca a praça no centro dos temas da cidade histórica, tratando-a como uma área sensível e de extraordinária importância no contexto das políticas de requalificação urbana.

Constatamos, porém, que, em todos os casos, a intervenção em praças no âmbito europeu tem sido orientada por uma clara matriz patrimonialista. Ou seja, como já descrevemos anteriormente, os processos de aproximação ao projeto têm como ponto base a análise e a compreensão do contexto histórico e patrimonial como instrumento orientador e operativo para a adaptação às novas exigências e usos da contemporaneidade. Apesar dessa raiz comum, que corresponde à primeira fase do processo de intervenção, e sem querer analisar caso a caso, verificamos que as escolhas de projeto têm seguido, na generalidade, três linhas orientadoras principais, todas elas enquadráveis numa atitude extremamente crítica, que orienta o modus faciendi: uma de orientação contextualista/conservacionista; outra, de caráter "historicista", buscando referências não no passado imediato, mas sim em épocas anteriores; e outra ainda, aberta a uma ruptura/ interpretação que possibilite a reinvenção e "correção" do espaço e sua recolocação no contexto atual.

Para ser mais fácil explicar essas três atitudes críticas no âmbito dos processos operativos de reformulação de uma praça em contexto patrimonial, apresentamos agora tês exemplos concluídos nos últimos 20 anos em Portugal, que ilustram claramente como, a partir de uma raiz de derivação comum, configuram-se três formas distintas de lidar e interagir com o património "não edificado" da cidade histórica.

\section{Intervenções na praça contemporânea: o contexto português}

No contexto português e salvo raras exceções (ao contrário de outros países europeus, como é o caso de Itália), a ausência de legislação nacional de referência contribuiu para o aumento da influência de documentos internacionais e da arquitetura de autor. Em consequência, existe hoje uma série de exemplos de intervenção marcadamente lusófonos, embora inseríveis em contextos mais vastos.

Se quisermos procurar um exemplo que conseguiu estabelecer um padrão de referência nos processos de reabilitação do património urbano, a Reabilitação do Centro Histórico de Guimarães é com certeza o caso mais emblemático.

Apesar de se tratar de uma intervenção à escala urbana, pareceu importante incluí-lo como exemplo, pelas questões leventadas e conclusões atingidas, facilmente interligadas e relacionáveis a casos mais pontuais de intervenção urbana como é o caso da praça. 
Projeto para a Requalificação do Centro Histórico de Guimarães

“Depois da 'renovação urbana' (nos anos 70) e da 'reabilitação urbana' (da primeira metade dos anos 80) Guimarães foi pioneira, no nosso país, na introdução e sustentação de estratégias 'de conservação do património urbano'” (AGUIAR, 1998, p. 4).

Tudo começou em 1979, com a elaboração do Plano Geral de Urbanização da mesma cidade, desenvolvido pelo arquiteto Fernando Távora, que, relativamente ao centro histórico,

[...] propõe uma visão qualificadora que não se restrinja apenas a monumentos ou conjuntos urbanos, mas antes se alargue, no espaço e no tempo, bem como no próprio significado seu conceito, a toda a área urbanizada, sugerindo também a preservação de outros valores que não edifícios e preconizando que essa área fosse considerada como "valor cultural" (FERRÃO, 1996, p. 687).

Ou seja, para encontrar um ponto de partida metodológico para os casos contemporâneos de intervenções em praças em contexto patrimonial português, somos conduzidos até a este exemplo mais abrangente e integrador de uma política de intervenção que não se limita ao caso específico, mas pretende procurar ao longo do processo e da obra as linhas diretoras de atuação mais apropriadas de intervenção.

Em 1981, com a criação do Gabinete Técnico Local (GTL) de Guimarães, teve início o processo de reabilitação do Centro Histórico. Em colaboração com o arquitecto Fernando Távora, a arquitecta Alexandra Gesta é destacada para gerir e definir a estratégia da intervenção.

A ambição é criar um modelo de regeneração urbana com propósitos cívicos e políticos, aplicável a outros casos semelhantes.

Os responsáveis por este longo processo de intervenção não se limitaram a procurar linhas orientadoras para o restauro do edificado e metodologias operativas de intervenção no espaço público, mas, tendo em conta a falta de mão de obra qualificada, organizaram cursos de formação específicos sobre a construção tradicional e técnicas construtivas ancestrais, dando início a um processo de especialização profissionalizada, pronta a responder de forma qualificada a um projeto de restauro urbano: "Em Guimarães mais do que nos valores da troca investiu-se nos valores de uso e, mais do que em projeto novo, investiu no desenho construído em obra" (AGUIAR, 1998, p. 8).

Relativamente à renovação do espaço público, esta foi encarada como um motor qualificador de todo o corpo construído e indutor de novos investimentos privados, chamados, por sua vez, a participar neste grande processo valorizador da cidade, no qual a rua, o largo ou a praça fronteira tornavam-se verdadeira antecâmara, ou sala de estar, e os logradouros tantas vezes funcionavam como cozinha, ou creche (AGUIAR, 1998, p. 8).

Em 1989, concluiu-se o projeto de remodelação da Praça de Santiago por obra do GTL (Figura 1), assessorado pelo Arquiteto Távora e, entre 1994 e 1995, são finalizadas as obras de intervenção nas Praças Condença de Juncal e do Largo João Franco, segundo os projetos de Fernando Távora, desta vez como projetista responsável independente.

Nesses projetos, o granito como material de eleição inscreve a história do local nos pavimentos das praças. 0 especial tratamento dado à estereotomia cria uma subtil mudança cromática, capaz de sublinhar hierarquias e limites visuais entre as diferentes partes e de estabelecer os remates entre o piso e o edificado.

É de ressaltar ainda a resolução dos desníveis ou a criação de pilaretes e outros obstáculos, a comunicação no pavimento, com a toponímia inscrita conjuntamente com desenhos iconográficos,

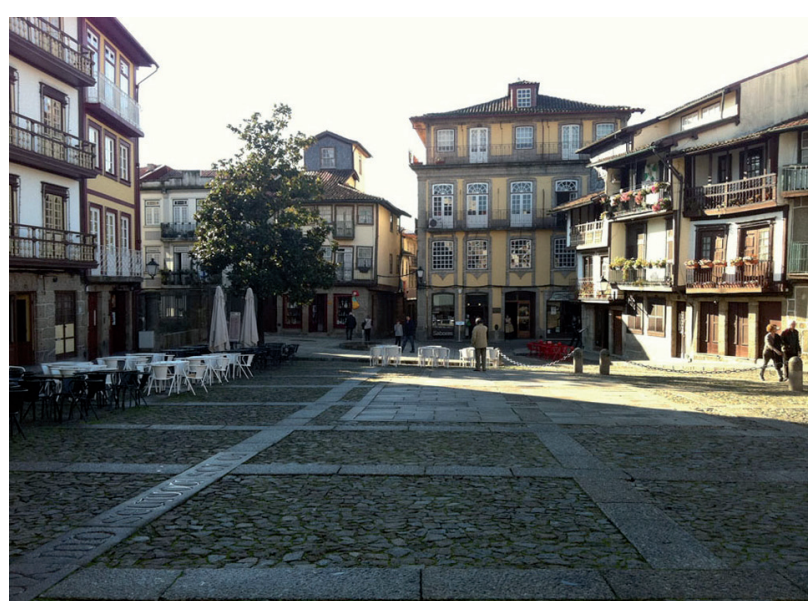

Figura 1 - Praça de S. Tiago, Centro Histórico de Guimarães, 2012 Fonte: Flavio Barbini, 2012. 
nomeadamente alusivos a elementos de arquitetura (BRANDÃO, 2002).

Em todo esse processo torna-se evidente como a atitude regeneradora dos responsáveis pelo projeto coloca-se numa posição de claro contextualismo/ conservacionismo em relação ao existente, sem querer criar rupturas, mas, pelo contrário, procurando uma harmonia plena, como se nunca, em época alguma, tivesse havido alguma intervenção no local, e onde "tudo atinge uma grande naturalidade", como afirma o arquiteto Souto de Moura (2012).

Agora tratamos de dois casos mais recentes, que estabeleceram um continuum metodológico em relação à experência de Guimarães: são eles o Projeto para a Requalificação da Zona Envolvente à Abadia de Santa Maria de Alcobaça e o Projeto para a Requalificação da Avenida dos Aliados e Praça da Liberdade, no Porto.

Projeto para a Requalificação da Zona Envolvente à Abadia de Santa Maria de Alcobaça, Alcobaça

Compreender a atual configuração da cidade de Alcobaça e o seu Rossio significa perceber não só a génese da Abadia Cisterciense, como a relação da sua formação com o território, o seu desenvolvimento, interação e modificação ao longo dos últimos séculos.

O projeto procura resgatar a relação de complementaridade entre a cidade e mosteiro, reaproximando ambos na zona envolvente ao monumento e propondo concretizá-lo no seu monumental terreiro.

As opções de projeto tomadas procuram privilegiar a preexistência em relação ao novo, resolvido de modo discreto, e lateralizando os novos espaços de apoio e serviços, bem como os sistemas e redes necessários à versatilidade do seu desempenho. Os materiais usados foram escolhidos para acentuar o despojamento hierático tão subjacente à arquitetura cisterciense, onde o modo de trabalhar a luz natural se figura tão decisivo [...] (OLIVEIRA, 2011, p. $8^{2}$ ).
Estamos perante um caso de reabilitação urbana único, em Portugal, num local que associa a um edifício com características ímpares (mosteiro Cisterciense fundado em 1153, pelo primeiro rei português, D. Afonso Henriques) um espaço vestibular de forma triangular que se vai diluindo nas suas extremidades.

0 projeto de remodelação da praça nasceu como natural extensão das intervenções em curso dentro do mosteiro cisterciense; não houve distinção entre interior e exterior. 0 impacto desta grande estrutura arquitetónica ultrapassa os limites das paredes exteriores projetando-se no espaço público e na própria cidade. 0 desenho do pavimento da praça nasceu a partir do desenho com blocos de pedra Ataija, dos canais de drenagem da água; elemento presente no local desde a sua fundação (Rio Alcoa e Rio Baça). O restante pavimento em saibro tinha os pressupostos de servir para uma área multifuncional, com possibilidade de receber um conjunto de funções prestes a ocupar o espaço, além disso deveria ter um caráter de reversibilidade, que um pavimento mineral não podia ter (CAMPOS, 2012).

As opções dos autores revelam o domínio do espaço e uma grande capacidade de selecionar os marcos decisivos e as opções a tomar.

A história do local não limita a intervenção mas, pelo contrário, representa um motor decisivo para tomar decisões críticas sobre o existente, buscando em épocas anteriores o rumo as decisões de fundo; uma atitude que podemos chamar "historicista", ou seja o passado não é visto como um continuum lógico que deve ser tomado com verdadeiro e adequado a todo o custo, mas é algo de selecionável e revisitável para que a escolha a fazer seja o mais criteriosa possível em busca de um forte caráter identitário (Figura 2).

A recolocação do grande terreiro em saibro que remete à época da fundação do próprio espaço, como alternativa ao "arranjo" do século XX, que ocultava a leitura do espaço bem como a do mesmo mosteiro, acompanha a escolha metodológica tomada.

\footnotetext{
2 Em entrevista a Gonçalo Byrne.
} 
Esse novo grande espaço é proposto agora livre de obstáculos para a devolução da dignidade da "fachada-palácio" do mosteiro. 0 redesenho de todo o espaço com grandes e espessas lajes de pedra marcando os caiais de água que atravessam o Rossio, bem como o mobiliário urbano e todas as pavimentações das ruas e largos de acesso a ele conferem nova identidade a todo o complexo e são agora os novos elementos catalisadores e de conexão do centro da cidade, são os pontos de partida de uma intervenção profunda, para a reafirmação da cidade que pretende ser mais atrativa (Figura 3).

A ideia do "vazio" do grande Rossio, ganha aqui força e ação, transformando-o no protagonista de um novo lugar sem tempo, onde todos os elementos contribuem para a celebração desse grandioso espaço público (BARBINI, 2011).

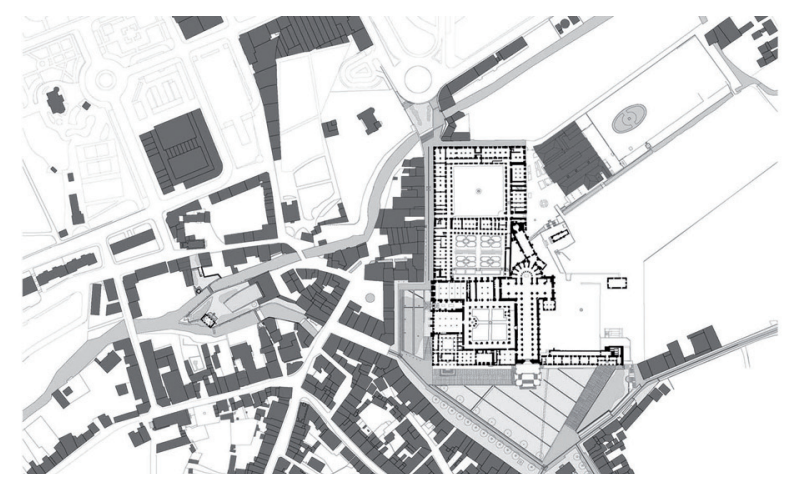

Figura 2 - Planimetria do Projeto para a Requalificação da Zona envolvente à Abadia de Santa Maria de Alcobaça, Alcobaça, desenho cedido pelo ateliê do arquiteto Gonçalo Sousa Byrne

Fonte: Ateliê Gonçalo Byrne, 2002.

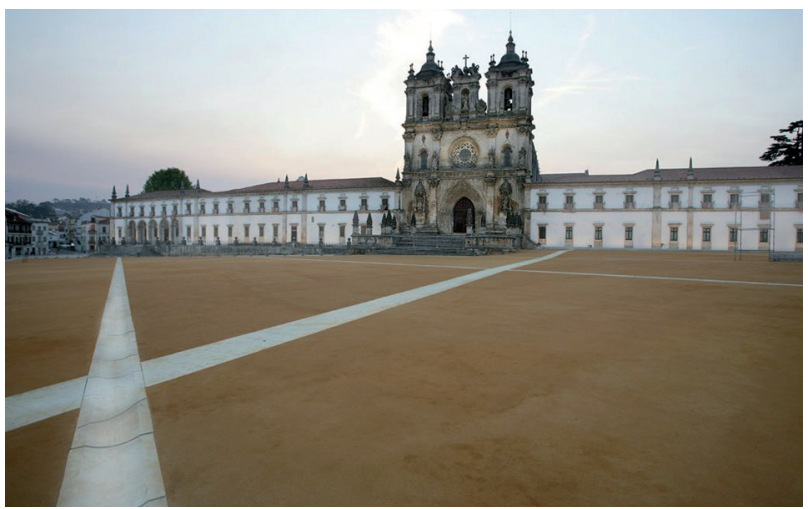

Figura 3 - Zona envolvente à Abadia de Santa Maria de Alcobaça, Alcobaça, 2011

Fonte: Ateliê Gonçalo Byrne, 2003.
Projeto para a Requalificação da Avenida dos Aliados e Praça da Liberdade, Porto

No que se refere à Avenida dos Aliados, a reconstrução do que existia é inviável, já que a largura da placa central e a espessura dos canteiros devem ser diminuídas; o que não permite recuperar a escala do jardim.

O projeto propõe a definição de um espaço contínuo (Praça da Liberdade - Avenida do Aliados) no qual a reformulação dos elementos vegetais privilegia o adensamento arbóreo, libertando o solo pavimentado. Esta opção dá "lugar" a um grande espaço público, a exemplo do que acontece em inúmeras cidades, respondendo a um uso que na prática, mas em condições precárias, já se verifica; tornando-o próprio do quotidiano da cidade, mais do que referido a alguns momentos de expressão coletiva [Figura 4].

0 projeto propõe o redesenho do mobiliário urbano, incluindo cobertos de paragens, bancos, recipientes de lixo. Na iluminação pública serão reutilizados os antigos e em parte existentes candeeiros, recuperados e otimizados em termos de qualidade e intensidade de luz. (MOURA, 2006, p. 1).

A Avenida dos Aliados é o resultado de um projeto urbano da cidade do Porto, encomendado ao arquiteto inglês Richard Barry Parker (1867-1947) em 1915, que pretendia "[...] abrir e ampliar uma parte da cidade que está muito congestionada, abrir uma ampla avenida que deverá ser, sobretudo muito dignificante. Rasgar o centro da cidade e criar um

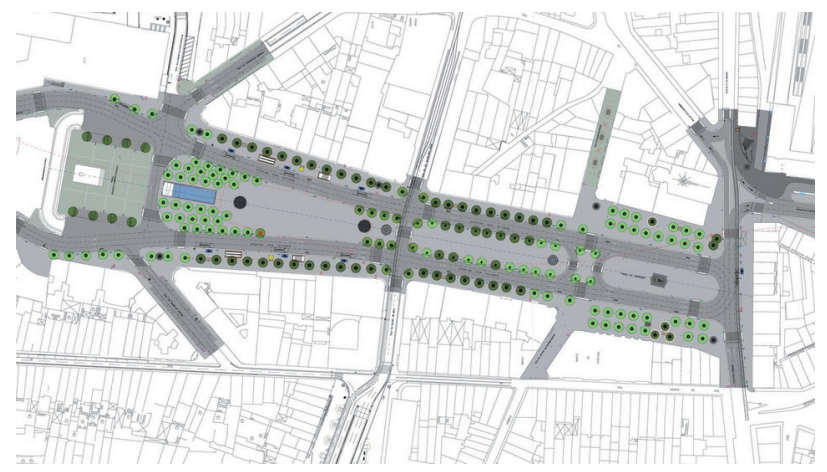

Figura 4 - Planimetria do Projeto para a Requalificação da Avenida dos Aliados e Praça da Liberdade, Porto, desenho cedido pelo ateliê do arquiteto Eduardo Souto de Moura

Fonte: Ateliê Souto de Moura, 2006. 
verdadeiro centro cívico e um centro de estabelecimentos" (TAVARES, 2009, p. 1).

A ambição do desenho estendia-se aos edifícios que ladeavam a avenida, seguindo um caráter neoclássico, ainda que, posteriormente, tenham sido edificados inspirados por modelos Beaux-Arts (Figura 5).

A avenida era composta por uma plataforma central ajardinada, com faixas laterais para a circulação de veículos e passeios em calçada de calcário com desenhos em basalto. Sua recente reformulação adveio "da necessidade de reconstruir o lugar de três estações de metropolitano contíguas: São Bento, Aliados e Trindade" (MOURA, 2006, p. 1).

As exigências infraestruturais remetiam para uma reformulação do desenho do espaço público, com redução das faixas de rodagem. Outras reflexões de ordem funcional conduziram os autores para uma aposta global de uniformização cromática superficial (em cubos de granito) para passeios e ruas, garantindo, assim, forte caráter identitário de um novo e extenso espaço público que, ao longo de sua história, viveu sempre dividido na ambiguidade entre uma praça e uma avenida.

0 resultado final é de um grande espaço cosmopolita, "encerrado", flexível sem barreiras, livre de obstáculos, vocacionado para o passeio, para o atravessamento e para eventos culturais, onde o cenário diversificado de matriz Beaux-artiana dos edifícios reflete-se nele, ganhando protagonismo e força expressiva. 0 desenho de toda a superfície é de grande rigor e cuidado, não se impõe, deixa-se absorver

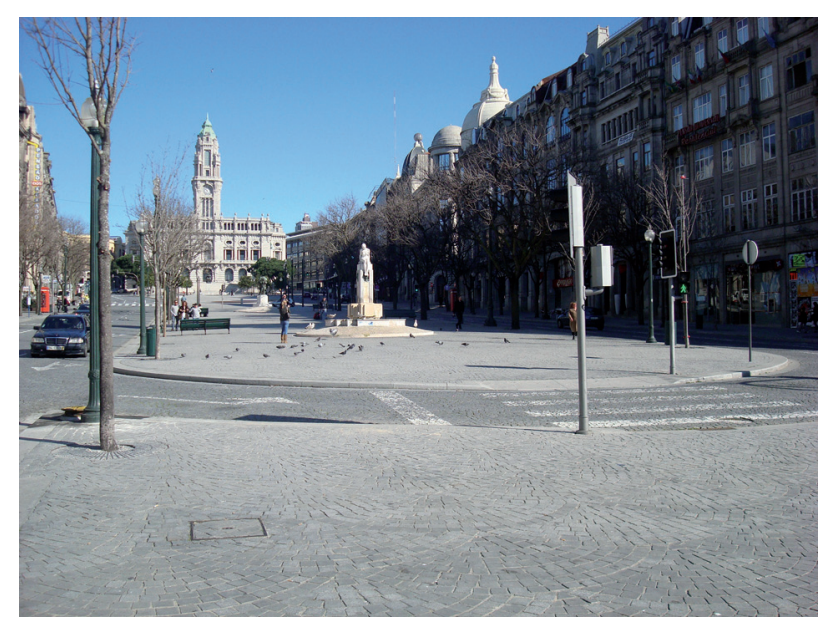

Figura 5 - Avenida dos Aliados e Praça da Liberdade, Porto, 2012 Fonte: Flavio Barbini, 2011. até aos embasamentos graníticos dos edifícios, num todo homogêneo. A tímida avenida idealizada por Barry Parker, associada a uma indefinida Praça da Liberdade, desaparece, deixando espaço para uma nova grande praça, desta vez dimensionada à escala da cidade.

Os arquitetos Alvaro Siza e Eduardo Souto de Moura agem aqui de forma radical, atuando uma ruptura clara em relação ao passado. Transformam a tipologia do espaço, estabelecendo novo patamar de referência para a memória e a perceção do local.

0 pragmatismo dos projetistas leva-os a reaproveitar candeeiros existentes, reintegrando-os no novo desenho. A arborização criteriosamente localizada nos largos passeios, e em outras áreas centrais, transporta-nos para a época oitocentista, deixando-nos imaginar um outro ponto de partida, quando, na verdade, tudo começou (BARBINI, 2011).

Considerações finais: levantamento de hipóteses de investigação para o mundo lusófono

Ao longo desse breve percurso, conseguimos encontrar as matrizes culturais e tipológicas da praça. Descobrimos que a ágora e o fórum foram os pontos de partida para a definição deste espaço público vital para as atividades públicas e de comércio de todas as civilizações do ocidente. Em muitos casos, a praça foi o elemento gerador do grande esforço de antropização do território - veja-se o caso das novas cidades de fundação na Europa, ou ainda as novas praças portuguesas das cidades do século XIII, criadas a partir da demolição de grandes quarteirões.

Todas essas praças chegaram a nossos dias com uma grande carga simbólica e de memória, valorizadas pelas indicações expressas na Carta de Veneza, que estimulou, no decurso de processos de refuncionalização, sua preservação e patrimonialização. Nos últimos 20 anos, um conjunto de estratégias de intervenção tem procurado novas formas de ação para recolocar a praça no contexto urbano contemporâneo, como centro de convergência social, polo de atração e de deslumbramento do cenário arquitetónico, por sua vez, já património da cidade.

Nesse contexto, o caso português é um exemplo emblemático, pela sua clareza na abordagem do tema e pelas metodologias assertivas implementadas. 
A partir dos anos 80, as intervenções para a reformulação de espaços públicos em áreas históricas consolidadas têm seguido três princípios de ação: de cariz contextualista/conservacionista; outro, de carácter historicista, buscando referências em épocas anteriores; e outro ainda, aberto a uma ruptura/ interpretação que recupere um novo espírito, nunca alcançado em épocas anteriores.

Todas essas ações resultam válidas enquanto fruto de avaliação e síntese crítica, aptas a reconsiderar a estrita relação entre o "vazio" e seus limites, agora valorizados como novos protagonistas do renovado "teatro urbano contemporâneo".

Visitei Guimarães à noite uma dúzia de semanas atrás, e o que achei notável foi que tudo o me pareceu natural era projeto do Távora [...]. A intervenção em Guimarães tem um desenho em que não se percebe o esforço do arquiteto, o esforço do autor. Tudo aquilo parece que esteja lá há muito tempo. É um domínio total sobre a topografia, a estereotomia e sobre as pedras, tudo atingiu uma grande naturalidade (MOURA, 2012).

Com essas palavras, o arquiteto Souto de Moura manifesta sua impressão sobre um projeto de recuperação assertivo e rico de significado, ponto de partida, gerador de uma metodologia clara, capaz de recolocar o espaço público da praça na contemporaneidade de forma natural, em continuidade com a recuperação identitária da cidade.

Essa manifesta "naturalidade" começa no próprio projeto, no momento em que tudo é analisado, medido e entendido. Um processo em que a cultura do lugar e a participação pública fazem parte do processo criativo, reinterpretando sinais tangíveis, que necessitam ser realçados e valorizados.

As intervenções nas praças de Alcobaça e no Porto, por sua vez, refletem essa atitude erudita e pragmática. Garantem um padrão de referência, duas atitudes diferentes, aplicáveis a outros casos, abrindo a porta a uma nova sensibilidade que considera o espaço da praça como se fosse a "joia" da cidade e ainda a grande "arquitetura vazia da cidade" (RIBAS PIERA, 2007, p. 51).

Neste ponto, abre-se um novo território de investigação, que ultrapassa as fronteiras europeias para atingir bases para um projeto futuro de investigação congénere no espaço da lusofonia, levantando as questões fundamentais para o estudo de eventuais semelhanças e dissemelhanças, que possam conduzir ao estudo de uma hipótese de existência de lusofilias urbanas contemporâneas dentro desta temática.

\section{Referências}

AGUIAR, J. G. (Re)habitação e conservação do património urbano. In: CONFERÊNCIA RE-HABITAR CENTROS ANTIGOS, 1998, Lisboa. Actas... Lisboa: Associação do Arquitectos Potugueses, 1998.

ALMEIDA, R. V. de. "As coordenadas de um mundo melhor": praças e cultura urbana na Idade Média e Renascimento. In: COLÓQUIO INTERNACIONAL ESPAÇO PÚBLICO: O LUGAR DA PRAÇA NA CIDADE CONTEMPORÂNEA, Lisboa, 2012. Atas... Lisboa: Departamento de Arquitectura da Universidade Autónoma de Lisboa, 2012. No prelo.

AUDRERIE, D. Quéstions sur le patrimoine. Bordeaux: Éditions confluences, 2003.

AVETA, C. Piero Gazzola. Restauro dei monumenti e conservazione dei centri storici e del paesaggio. 255 f. Tesi (Dottorato di ricerca in Conservazione dei Beni Architettonici) - Universitá degli Studi di Napoli Federico II, Napoli, 2005.

BARBINI, F. A praça: um património a preservar e valorizar. In: SIMPÓSIO PATRIMÓNIO EM CONSTRUÇÃO, Lisboa, 2011. Atas... Lisboa: LNEC, 2011.

BRANDÃO, P. (Coord.). 0 chão da cidade. Lisboa: Centro Português de Design, 2002.

CAMPOS, J. P. F. de. Entrevista não publicada. Lisboa, 2012.

CATANESE, A. J.; SNYDER, J. C. Urban Planning. New York: McGraw Hill, 1979.

CHOAY, F. A alegoria do património. Lisboa: Edições 70, 2000.

CONZEN, M. R. G. (Ed.). Thinking about urban form: papers on urban morphology, 1932-1998. Bern: Peter Lang AG; European Academic Publishers, 2004.

DENTI, G. Spaziocollettivo e società. Firenze: Allinea, 1985. 
FERRÃO, B. Uma perspetiva sobre a evolução do conceito de património arquitectónico na cultura vimaranense. In: CONGRESSO HISTÓRICO DE GUIMARÃES, 2., 1996, Guimarães. Atas... Guimarães: Ed. C.M.G.; U.M., 1996.

GROHMANN, A. La cittàmedievale. Bari: Laterza, 2003.

GROS, P.; TORELLI, M. Storia dell'urbanistica, il mondo romano. Bari: Editori Laterza, 2010.

GUIDONI, E. La Città dal medioevo al Rinascimento. Bari: Laterza, 1989.

GUIDONI, E. (Org.). Gli spazi, i monumenti, i materiali: storia e interpretazione. In: BARBIANI, L. (Org.). La piazza storica italiana: analisi di un sistema complesso. Venezia: Marsilio, 1992.

LEFÉBVRE, H. La production de l'espace. Paris: Anthropos, 1986. (Obra originalmente publicada em 1974).

MILHEIRO, A. V. Praças do Império no espaço colonial português no Estado Novo - a regra e o modelo. In: COLÓQUIO INTERNACIONAL ESPAÇO PÚBLICO: O LUGAR DA PRAÇA NA CIDADE CONTEMPORÂNEA, 2012, Lisboa. Atas... Lisboa: DA/UAL, CEACT/UAL e IUL - CIAAM e Dinâmia-CET, 2012. No prelo.

MOURA, E. S. de. Memória descritiva do projeto. Porto: [s.n.], 2006.

MOURA, E. S. de. Fernando Távora - entre a inquietude e a serenidade. Porto: TSF, 2012.
OLIVEIRA, S. "Entrevista a Gonçalo Byrne". Revista Arte \& Construção, edição especial Reabilitação, p. 8, ago. 2011.

RIBAS PIERA, M. R. The Architecture of the square. In: MANCUSO, F. (Coord.). Squares of Europe, places for Europe. Venezia: Jagiellonian University Press, 2007.

RAMALHETE, F. (Coord.). Praça do Comércio, perceção e representação do espaço: presente e futuro. Lisboa: EDIUAL, 2009.

SITTE, C. Arte di costruire le città. Firenze: Jaca Book, 2007.

SOCIEDADE PARA A PRESERVAÇÃO DO PATRIMÓNIO SPCC. Tradução: Fernando M. A; Henriques e Virgolino F. J. “Textos fundamentais". Cadernos SPPC, n. 1, jan. 1996.

TAVARES, R. Avenida dos aliados, cíclo obra aberta. Lisboa: Ordem dos Arquitetos SRN, 2009.

TEIXEIRA, M. (Org.). A praça na cidade portuguesa. Lisboa: Livros Horizonte, 2001.

Recebido: 30/05/2012

Received: 05/30/2012

Aprovado: 19/10/2012

Approved: 10/19/2012 